\title{
The Idea and Realization of Higher Vocational Teaching Reform Based on Outcome-oriented Education
}

Tianxiao Song*

Huizhou Economics and Polytechnic College, Huizhou 516057, Guangdong province, China. E-mail: 983964492@qq.com

\begin{abstract}
Higher vocational education requires reform and innovation. It is necessary to attach importance to the process and results of higher vocational education and obtain the international engineering education professional certification. Outcome Oriented Education (OBE) is based on the premise that all students can be successful, clarifies the learning outcomes of students after the education process, and emphasizes the ability of students to apply what they have learned to practice through action learning. Soon after the birth of OBE in the United States, it set off a huge wave of education reform. The transformation and promotion of OBE's localization will surely develop a new normal of vocational education with distinctive features, outstanding advantages, and outstanding results. In the final analysis, the OBE model puts students at the center of the classroom. As a successful teaching model exploration institution, the school takes the learning achievements as the starting point to carry out the behavior process of students' various practical application skills training. When implementing OBE, only a deep understanding of the connotation structure of the outcome-oriented pyramid can prevent misunderstanding or distortion of the original meaning.
\end{abstract}

Keywords: Outcome Oriented; Teaching Reform; Higher Vocational Teaching

\section{Introduction}

In the era of popularization of higher education, domestic vocational education has done a lot of research and exploration, such as work process-oriented teaching method, project teaching method, task-driven teaching method, etc., and it has achieved fruitful results. Shortly after the birth of Outcome-Oriented Education (OBE) in the United States, it set off a huge wave of education reform ${ }^{[1]}$. One of the attractions of OBE is that it can provide managers with some control over educational results, and it also allows teachers to freely choose the content and methods that help students achieve the desired results ${ }^{[2]}$. In the past, in the various professional classrooms of higher vocational colleges, the dominant position was always the teachers, and the students passively received knowledge points for a long time. In contrast, the result-oriented education model advocates making students become masters in the classroom. OBE is student-centered and ability-oriented. It emphasizes that every student has talents. It advocates that everyone can succeed. Learning should be based on cooperation rather than competition. Schools and teachers should provide students with a clear blueprint for learning outcomes. Students successfully create opportunities and environments ${ }^{[3]}$. The OBE model returns the dominance of teaching to students, and its focus is on students' learning results and emphasizes students' practical ability ${ }^{[4]}$. Therefore, only by making good use of teaching methods can we carry out reasonable curriculum design under the OBE mode.

The input and output of education are not directly proportional, prompting people to begin to reflect on the effec-

Copyright (C) 2021 Tianxiao Song

doi: $10.18686 / \mathrm{mmf} . v 5 \mathrm{i} 1.3168$

This is an open-access article distributed under the terms of the Creative Commons Attribution Non-Commercial License

(http://creativecommons.org/licenses/by-nc/4.0/), which permits unrestricted non-commercial use, distribution, and reproduction in any medium, provided the original work is properly cited. 
tiveness of education input. As a new concept of vocational education, OBE is guided by the learning results that students have finally achieved through the educational process, emphasizing what students can do after learning, rather than what they have learned ${ }^{[5]}$. The OBE concept and curriculum teaching development theory have always attracted much attention, and have been valued and recognized by the majority of educators and researchers in the vocational education field. On the premise that all students can be successful, OBE clarifies the learning results obtained by students after the educational process, and emphasizes the ability of students to apply the learned content to practical use through action learning ${ }^{[6]}$. In the final analysis, the OBE model puts students at the center of the classroom. As a successful teaching model exploration institution, the school takes the learning achievement as the starting point to carry out the behavioral flow of students' various practical application skills training ${ }^{[7]}$. The transformation and promotion of OBE's localization will surely develop a new normal of vocational education with distinctive features, outstanding advantages, and outstanding results. Therefore, it is of great significance to study the implementation of higher vocational curriculum reform based on result-oriented. When implementing OBE, only a deep understanding of the theory on which it relies and the connotation structure of the result-oriented pyramid cannot misunderstand or distort the original meaning.

\section{The Connotation of Outcome-Oriented Education and Higher Vocational Teaching Method}

The OBE Pyramid covers all the ideological connotations of OBE. It is not only a rational grasp of OBE, but also an action guide to promote OBE reform. As a qualified teacher in higher vocational colleges, in the early stages of promoting the OBE model, he must ensure a meticulous grasp of the overall cognitive abilities and academic conditions of the students in the class, and at the same time rely on rich social life materials as the basic auxiliary medium. Carry out the improvement and repair of the existing teaching content. OBE requires teachers to clearly focus on the final learning outcomes that students can achieve after a period of learning experience. The task of teachers is to help students develop knowledge, skills and personalities so that they can achieve expected results. In the process of adopting the result-oriented education model for all kinds of professional teachers in higher vocational colleges, they must fully consider the students' real life experience needs, and at the same time assist them in vividly interpreting familiar life situations ${ }^{[8]}$. In order to ensure that all students can succeed, OBE pays full attention to the differences of students' personality and emphasizes that it is not necessary to provide all students with the same learning opportunities in the same way at the same time, requires all students to achieve success at the same moment. The contextualization of teaching activities is to urge teachers to organize students to quickly intervene in a social environment close to the real state based on the design and use of various vivid teaching and guidance situations, and to learn how to think scientifically in the various action learning processes, perception and experience, and finally all the indirect and direct experience that they harvested interactively.

OBE requires schools and teachers to respond to students' different needs in a flexible manner, provide students with alternative learning resources fairly and establish a multi-evaluation mechanism, so that students can display learning results in a variety of ways. On the premise that all students can succeed, OBE establishes conditions and provides opportunities for students to achieve expected learning outcomes, emphasizing what students not only have to learn, but more importantly, the construction of practical abilities can be applied to them. The curriculum system is constructed according to the above requirements and the implement teaching. Restricted by enrollment conditions, higher vocational colleges have stricter teaching management systems than that of undergraduate colleges. Those students who fail to be selected from college admissions are relatively lacking in the ability of autonomous students ${ }^{[9]}$. This requires teachers to emphasize more appropriate education in the teaching process, and the inculcation of teaching content and the coordination of the classroom environment have become the responsibility of every higher vocational teacher. OBE expects and allows all students to study successfully. High expectations do not mean lower performance standards, but it emphasize that schools should adopt high-level courses and high-level performance standards. Teachers must be committed to improving the acceptability of standards, creating good learning situations, making good use of different 
teaching methods, encouraging different learning methods, and guiding students to achieve higher achievements in the challenging learning process. OBE requires accurate learning outcomes measurement and evaluation, to evaluate learning results in stages and determine new goals for advancement, which also emphasizes positive incentives for students. And the evaluation results are measured by the standard for achieving the highest performance achievement, and it does not emphasize the comparison of results between students.

OBE emphasizes the integration of curriculum framework, teaching, tests and certificates, and advocates interdisciplinary and cross-grade courses combined with life situations. OBE concept emphasizes taking students as the center, serving students, not giving up each student, evaluating students individually, and allowing students to enjoy educational achievements. It not only pays attention to students' learning achievements during school, but also pays attention to students' achievements after graduation, so as to truly track and feedback and continuously improve and diagnose the whole teaching process. OBE believes that all teachers and students should have the opportunity to learn and teach successfully. Schools should divide the process of achieving peak results into several stages, and set sub-goals of results in stages, so that students can gradually achieve peak results in the process. Effective classroom teaching is not only the guarantee to achieve the expected ability and the established learning goal, but also the foundation to enable students to achieve the training goal and meet the graduation requirements. According to different students, it is necessary to determine the learning objectives of each stage, formulate different teaching programs and provide different learning opportunities according to different requirements.

\section{The Application Strategy of Outcome-Oriented Education Model in Higher Vocational College}

\subsection{Ensure the appropriateness of the selection and use of teaching methods}

The teaching methods that can be introduced on the basis of the results-oriented model are extremely rich and varied, but not all methods are applicable to the higher vocational students. In the process of selecting and using this part of teaching mode, it is necessary for teachers to select a targeted and coordinated teaching guidance mode in combination with the signs of differences in teaching links. Education quality is the evaluation of education level and effect, which is finally reflected in the quality of training objects. The quality of education is result-oriented, the standard of education quality is applicable, and the aim is to promote students' all-round development, which has become an important orientation of the reform policy of educational powers ${ }^{[10]}$. OBE concept follows the principles of reverse design and continuous improvement. Based on the results of the needs of enterprises and society, the training objectives are decided first, then the graduation requirements are set by the training objectives, then the curriculum system is set according to the graduation requirements, and finally the teaching resources are rationally allocated according to the curriculum system.

\subsection{Pay more attention to the process design of classroom teaching}

OBE theory merges with the general trend of international vocational education. At present, it is not only a timely starting point for Chinese higher vocational colleges to innovate in theory and practice, but also a pleasing preface for Chinese vocational education to call the world brand. The teaching model based on results orientation pays great attention to the design of various working procedures in teaching units, and the specific role played by teaching methods is to ensure the successful completion of all teaching links. Teachers' teaching should be based on students' real life experience, and direct life experience should be introduced into knowledge learning. Through learning activities, students can get the feeling and experience from direct experience, which can be transferred, internalized and applied. Under the result-oriented concept, diversified teaching objectives and various teaching and learning methods determine the diversification of evaluation ${ }^{[11]}$. In the process of developing and designing teaching links, the results-oriented teaching mode pays great attention to project teaching, that is to say, each class is set as an important task, while students are guided by the links according to the necessity of teachers' design, and continue to explore and sort out the final answers to related questions. 


\subsection{Promote the renewal of teaching methods}

OBE concept is open and inclusive, which adapts to the future of higher vocational education. The teaching guidance mode under the result-oriented teaching mode usually chooses project-driven as the basic teaching method, and then encourages students to quickly intervene in their own roles, and finally implements the clear motivation of teaching with the help of practical tasks as the dynamic index. OBE is a kind of educational idea and method, not a fixed mode, and it has strong compatibility. OBE believes that no curriculum model is completely suitable or perfect, but it can be confirmed that organizing these models can help curriculum designers to clarify the ways used in curriculum design. Therefore, different curriculum design models should be adopted according to the objectives and the nature of teaching materials. In the final analysis, the core of OBE-based teaching method is to guide students to master efficient learning methods, that is, to exercise students' awareness of autonomous and in-depth learning and their flexibility and adaptability.

\section{Conclusions}

On the surface, OBE is concerned about the changes reflected in students' behaviors, and critics can't help blaming OBE for neglecting humanistic spirit. In fact, this is a misunderstanding of OBE. The teaching methods that can be introduced on the basis of the results-oriented model are extremely rich and varied, but not all methods are applicable to the higher vocational students. The method determines the result. Without a correct and reasonable method, the teaching link will not be carried out, so the OBE model will not show gratifying results. In practice, OBE has completed the perfect combination of pragmatism and teleology, taken students as the center of design, and formed a set of unique language rules and exquisite curriculum system. The teaching model based on results orientation pays great attention to the design of various working procedures in teaching units, and the specific role played by teaching methods is to ensure the successful completion of all teaching links. In the final analysis, the core of OBE-based teaching method is to guide students to master efficient learning methods, that is, to use diversified teaching guidance channels.

\section{References}

1. $\mathrm{Xu} \mathrm{F}$. Exploration of the teaching evaluation reform of teachers in higher vocational colleges based on results. Modernization of Education 2017; 4: 60 - 61.

2. Wang X, Tian W, Chen G, et al. The theoretical connotation of outcome-oriented education and its enlightenment to higher vocational education reform. Vocational and Technical Education 2018; 39(8): 26 - 31.

3. Roberts P. Higher education curriculum orientations and the implications for institutional curriculum change. Teaching in Higher Education2015; 20(5): 542 - 555.

4. Sun X, Lu Y, Yan Y, et al. Research and Implementation of Higher Vocational Teaching Reform Based on Outcome-oriented Education. Liaoning Higher Vocational Journal2019; 21(10): 43 - 46.

5. Kang Y. Research on higher vocational Chinese teaching reform based on results orientation. Journal of Huainan Vocational and Technical College 2020; 20(2): 77 - 79.

6. Diao A. Using information-based teaching to promote achievement-oriented higher vocational pharmacy teaching reform. Health Vocational Education 2019; 37(8): 45 - 47.

7. Zhang Z. Research on higher vocational accounting teaching reform based on results orientation. Heilongjiang Science 2018; 9(8): $60-61$.

8. Zhao H, Zhang Y. Teaching Reform and Practice of Higher Vocational Management Accounting Course Based on Results Orientation. Business Accounting 2020; 679(7): 108 - 110.

9. $\mathrm{Xu}$ J. Research on the Reform of Police Administrative Law Curriculum in Public Security Higher Vocational Colleges under the Educational Philosophy of Achievement.

10. Zou J, Liu X, Mou X. The design and implementation of achievement-oriented teaching in higher vocational education. Chinese Vocational and Technical Education 2018; 672(20): 27 - 33.

11. Zha Y, Zhu Q. Project-based teaching design for higher vocational education based on results. Vocational Education Research 2019; 185(5): 70 - 75. 